
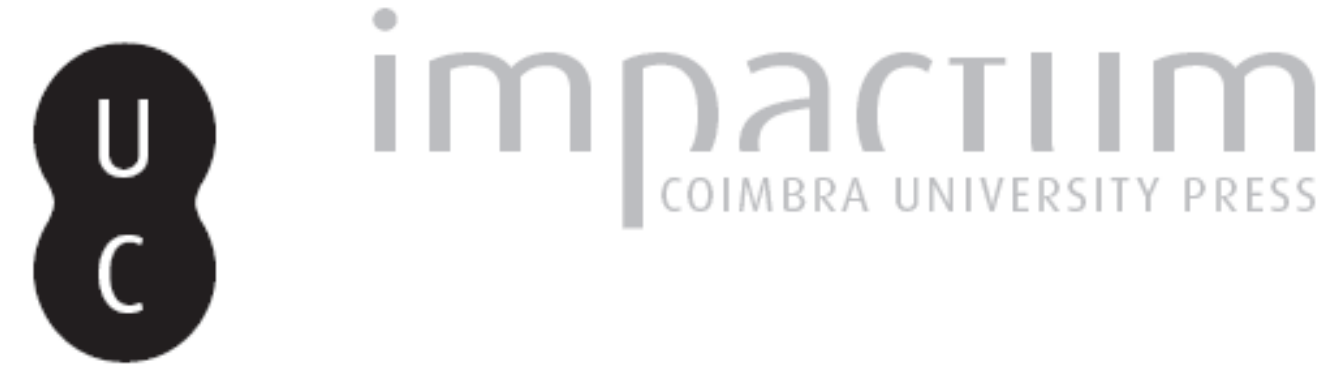

\title{
Por mosaicos nunca dantes navegados: sobre a iconografia da nave de Ulisses do mosaico de Santa Vitória do Ameixial
}

Autor(es): $\quad$ Alves, Francisco J. S.

Publicado por: Imprensa da Universidade de Coimbra

URL

persistente:

URI:http://hdl.handle.net/10316.2/45488

DOI:

DOI:https://dx.doi.org/10.14195/1647-8657_32_33_14

Accessed : $\quad$ 26-Apr-2023 11:28:47

A navegação consulta e descarregamento dos títulos inseridos nas Bibliotecas Digitais UC Digitalis, UC Pombalina e UC Impactum, pressupõem a aceitação plena e sem reservas dos Termos e Condições de Uso destas Bibliotecas Digitais, disponíveis em https://digitalis.uc.pt/pt-pt/termos.

Conforme exposto nos referidos Termos e Condições de Uso, o descarregamento de títulos de acesso restrito requer uma licença válida de autorização devendo o utilizador aceder ao(s) documento(s) a partir de um endereço de IP da instituição detentora da supramencionada licença.

Ao utilizador é apenas permitido o descarregamento para uso pessoal, pelo que o emprego do(s) título(s) descarregado(s) para outro fim, designadamente comercial, carece de autorização do respetivo autor ou editor da obra.

Na medida em que todas as obras da UC Digitalis se encontram protegidas pelo Código do Direito de Autor e Direitos Conexos e demais legislação aplicável, toda a cópia, parcial ou total, deste documento, nos casos em que é legalmente admitida, deverá conter ou fazer-se acompanhar por este aviso.

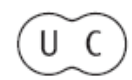




\section{UNIVERSIDADE DE COIMBRA \\ FACULDADE DE LETRAS}

\section{CONIMBRIGA}

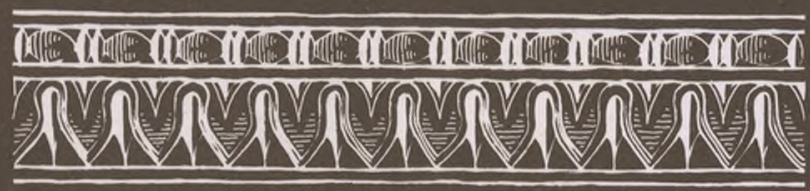

VOLUMES XXXII-XXXIII-1993/94 
Francisco J. S. Alves

Director do Museu Nacional de Arqueologia

Presidente da direcção de ARQUEONÁUTICA Centro de Estudos

POR MOSAICOS NUNCA DANTES NAVEGADOS

SOBRE A ICONOGRAFIA DA NAVE DE ULISSES DO MOSAICO

DE SANTa Vitória do AMEIXIAL

«Conimbriga» XXXII-XXXIII (1993-1994), p. 247-261

Resumo: A cena de "Ulisses e as sereias", do mosaico do balneário da villa lusitano-romana de Santa Vitória do Ameixial foi já objecto de diversos estudos, mas alguns aspectos essenciais relativos à interpretação estrutural e funcional da embarcação propriamente dita não foram abordados sob todos os ângulos possíveis. Deve aliás ser tido em consideração um recente e oportuno questionamento sobre o seu valor como documento iconográfico em si mesmo, sem prejuízo do reconhecimento de uma vaga mas perceptível fonte de inspiração da cena em alguns mosaicos norte-africanos. $\mathrm{O}$ resultado parece traduzir uma autêntica colagem de elementos, no sentido técnico-artístico do termo, em que os traços de um modelo padrão parecem ter-se desvanecido perante uma improvisação provinciana de estilo marcadamente nä̈f possivelmente inspirada em modelos de barcos de tradição fluvial.

RÉsumé: La scène d' "Ulysses et les sirènes", de la mosaïque du balnéaire de la villa lusitano-romaine de Santa Vitória do Ameixial a été object de plusieurs études mais quelques aspects essentiels concernant l'interprétation structurelle et fonctionelle du navire lui-même n'ont pas été analysés sous tous les angles possibles. D'ailleurs il doit être pris en considération une récente intérrogation, avec de nouveux arguments, sur sa valeur en tant que document iconographique, bien qu'on puisse continuer à reconnaître la source d'inspiration de cette scène dans certaines mosaïques nord-africaines. Le résultat semble traduire un authentique collage au sens technique et artistique du terme, où les traces du modèle de référence se sont évanouis resultant une improvisation provincienne de style nettement naïf, probablement inspirée en modèles de bateaux de rivière. 
(Página deixada propositadamente em branco) 


\section{POR MOSAICOS NUNCA DANTES NAVEGADOS Sobre a iconografia da nave de Ulisses do mosaico de Santa Vitória do AmeixiaK ${ }^{1}$ )}

A cena de "Ulisses e as sereias", do mosaico do balneário da villa lusitano-romana de Santa Vitoria do Ameixial (Fig. 1), foi objecto de um aprofundado estudo (TORRES CARRo, 1978). Pareceria, portanto que, à primeira vista, pouco ou nada mais haveria a dizer sobre esta controversa representação. No entanto, apesar da profundidade deste estudo, certos aspectos essenciais relativos à interpretação estrutural e funcional da embarcação propriamente dita não foram abordados sob todos os ângulos possíveis, não sendo tido nomeadamente em consideração um recente e oportuno questionamento sobre o seu valor como documento iconográfico em si mesmo (BASCH, 1975).

Muito do que parece pois ainda poder ser dito sobre o assunto tem a ver com a reapreciação de alguns pormenores relativos à forma e orientação da embarcação representada. $O$ que, como se pretende demonstrar, é susceptível de permitir uma nova abordagem desta velha e multifacetada questão.

Alinhando a sua opinião por uma das tradicionais escolas interpretativas desta cena, Mercedes Torres Carro considera que a embarcação tem a proa à esquerda e que portanto navega neste sentido. Em apoio desta interpretação assinala que vela está tensa." (: 95), embora não indique a orientação deste enfunamento, certamente por

(') O presente trabalho é uma versão actualizada da comunicação apresentada em 1989 em Monforte, durante as II Jornadas do Nordeste Alentejano, cujas Actas não chegaram a ser publicadas. 
esta especificação lhe parecer óbvia; refere também o pormenor da característica ondulação que se forma à proa de qualquer barco sulcando as águas, as linhas (de tesselas paralelas entre si e descontínuas) adoptant formas curvas à volta da proa do barco, com o que dão a sensação realista de que esta sulca o mar” (: 101) - muito embora não assinale a incorrecta tradução do alinhamento do eixo da ondulação com o da embarcação. Indica igualmente que "a sua proa está rematada por uma cabeça de dragão que sai de um nó circular precedido por uma moldura cilíndrica. A popa prolongase num pescoço de cisne que se projecta fora do

Ora, se relativamente a este último elemento decorativo se pode admitir esta interpretação, que o assimila a um protomos zoomórfíco muito alongado - cujo elançamento, algo excessivo, se não mesmo incongruente é, aliás, pouco comum na iconografia - já a caracterização do outro elemento terminal pela A. parece inadequada. De resto, Luís Chaves, responsável pelas escavações de 1915-1916 no sítio, na publicação final destas (CHAVEs, 1938), identificara perfeitamente este elemento decorativo: "a proa, voltada para N.O., termina pelo aplustre ou aplustrum, ornato feito de pranchas de madeira com o aspecto de plumas" (: 54). De resto, ao invés do primeiro elemento decorativo, este é muito comum na iconografia da época romana, como se pode verificar, a título de exemplo, nos baixos-relevos do Museu Capitolino, do Palácio Spada e de Puzzoles. A este propósito cumpre no entanto assinalar a curiosa discrepância que se verifica quanto à localização deste elemento simbólico-decorativo nas representações destes baixos-relevos (à popa) e na da barca de Sta. Vitória (à proa, na opinião daqueles autores). De facto, em toda a iconografia compulsada sobre embarcações da época romana, em nenhum caso este elemento figura à proa, sendo sempre um elemento decorativo característico da popa.

Saliente-se também que Mercedes Torres Carro, depois de se referir aos quatro remadores da barca de Sta. Vitória, ao indicar que "... o quinto, colocado mais próximo da popa, não parece dirigir manobras, operação que lhe seria própria" (: 97), não sublinha a notória omissão da figuração do remo-leme, peça fundamental do aparelho de navegação na Antiguidade e elemento quase sempre merecendo especial destaque na iconografia da época - mesmo que frequentemente mal representado do ponto de vista funcional, com acontece ainda mais frequentemente com os próprios remos (HuMPHREYS, 1978). 
Por outro lado, a A. considera que se encontra vista de perspectiva aquela extremidade que interpreta como sendo a proa da embarcação, mas não se debruça sobre os respectivos pormenores, aliás particularmente interessantes do ponto de vista iconográfico. Com efeito, de acordo com esta interpretação, ter-se-ia de admitir que a posição da cinta de reforço lateral da proa, na parte de estibordo visível à vante, estaria incorrectamente traduzida, falhando a sua simetria com a peça idêntica de bombordo. Em contrapartida, pode ver-se a transcrição destes elementos de reforço de proa, numa perspectiva correctamente assumida, em galeras de pinturas murais de Pompeia (Fig. 3). Compreende-se, nesta ordem de ideias, que a A. faça a observação de que "há que ter em conta (...) que a perspectiva está em Santa Vitória pouco conseguida. Mostrase o barco de perfil, no entanto vê-se uma parte de bombordo que deveria ter ficado oculta. Este erro de realização dá ao barco dois pontos de vista. Inclusivamente pode observarse um terceiro ponto de vista, pois na cabine do timoneiro - que segue o perfil do barco - mostrase de frente a porta de acesso. Na realidade, esta perspectiva da cabina corresponderia a uma embarcação que tivesse a proa próxima do espectador e algo desviada à direita com respeito ao eixo do mosaico" (: 96-97). Mas repare-se aqui que a A. comete dois lapsos: o primeiro, ao designar por bombordo o lado da extremidade de vante "que deveria ter ficado oculta" (se a embarcação fosse representada rigorosamente de perfil, entenda-se); de facto, considerando a proa à esquerda, deveria ter dito estibordo e não bombordo; o segundo, porque a entrada da "cabine" (mais propriamente um toldo), só deveria ver-se numa perspectiva em que a popa (e não a proa, como diz a A.) estivesse próxima do espectador. Torna-se no entanto óbvio, independentemente destes lapsos, o comentário de que "o que desde logo é evidente é a imperícia do mosaicista, que se coloca manifestamente pelo desconjuntamento existente entre as diferentes partes do navio, traçadas todas elas de um ponto de vista diferente" (: 97).

Refere também a A., não sem razão, que "não podemos assimilar o tipo de embarcação que aparece em Santa Vitória com nenhuma das representações que conhecemos referentes a esta cenai" (: 95).

Saliente-se, como simples apontamento, que a representação de perspectiva não é no entanto assim tão rara, verificando-se numa grande diversidade de regiões, temas e suportes iconográficos, como por exemplo nos mosaicos de Preneste e Thugga, ou em pinturas murais de Pompeia. 
Alguma reserva merece porém o comentário da A. de que "em princípio poderia pensarse num navio de tipo comercial por levar velas e remos, mas nem a forma nem o tamanho parecem apoiar isto" (: 96); reserva que por razões análogas merece também a afirmação de Luís Chaves de que "pelo comprimento, e por Ulisses ser guerreiro esta navis pertence ao tipo dos navios de guerra" (: 54). Esta afirmação merece ser matizada porque a personagem de Ulisses, embora fundamentalmente assimilada a um guerreiro, pode-o ser também a um pirata ou a um aventureiro - embora deva reconhecer-se que o espaço do mito não obedece naturalmente às mesmas regras do espaço iconográfico, sendo que neste a figura do guerreiro é obviamente a mais expressiva. Aliás, é vasta a exegese histórico-literária sobre a questão da nave de Ulisses (veja-se a este propósito CAsson, 1971, Chap. X, Apendix 2 (“Odysseus boat"): 217-219).

De facto, a interpretação deste documento iconográfico parece justificar uma maior ponderação. $\mathrm{O}$ que não quer dizer que a representação da barca de Sta. Vitória ou o próprio tema não possam ser vistos, até simultaneamente, sob aqueles diferentes ângulos. Aliás, Claude Poinssot (1965), ao evocar a representação iconográfica da barca de Ulisses na série dos mosaicos norte-africanos onde a cena está representada - e à qual junta o mosaico de Sta. Vitória (: 223), refere que " $o$ barco de Ulisses é um compromisso entre uma galera e um veleiro" (: 220-221).

Saliente-se a propósito que "esta ambiguidade aponta de facto para uma das mais comuns inexactidões em representações de galeras antigas, o costume de mostrá-las a vela e a remo. Não seria de todo prático usar vela e remos ao mesmo tempo excepto talvez por breves periodos ao manobrar para entrar ou sair de um porto; e remos só podem ser usados se o barco estiver velejando muito devagar. Normalmente uma galera antiga usaria ou a sua vela ou os seus remos. Mas tinha ambos, portanto os pintores gostavam de pintar ambos. Isto não é, estritamente falando, um erro, mas o resultado de uma atitude para representar que difere de algum modo da nossa. Há menos ênfase no retratar exactamente o que um observador podia ver num ponto particular no tempo e no espaço, e mais preocupação em incluir todos os atributos básicos do objecto retratado" (HumpHreYs: 79). De facto, apesar da importância universalmente atribuída à documentação iconográfica, todos os autores são unânimes em reconhecer os seus limites, assim como a necessidade de se observar a maior prudência nas 
conclusões que delà se extraem. Em qualquer época, como se pode verificar no caso da iconografía naval portuguesa, a propósito do que João da Gama Pimentel Barata (1972 : 30, nota 3) refere: "Já os nossos três maiores arqueólogos navais aludiram sumariamente aos perigos $e$ precauções da interpretação da iconografia naval: Lopes de Mendonça (Estudos sobre navios portugueses nos Séc. XV e XVI. Lisboa, 1892, p. 40), Quirino da Fonseca (Memórias de arqueologia marítima portuguesa. "Anais do Clube Militar Naval", 46, 1915, p. 374), e Brás de Oliveira (Os navios da descoberta. Reed, do art. in "Revista Portuguesa Colonial e Maritima”, 1897, Lisboa, 1940, p. 23)".

No que respeita à iconografia naval de época romana, vale a pena referir o que a este propósito escreveram os autores de duas importantes e recentes sínteses de história naval daquela época: "...tenta-se interpretar os documentos figurados, não sem perigo: estes mostramse muitas vezes de utilização delicada, em virtude do seu carácter por vezes irrealista ou fantasista; muitos artistas criavam barcos, não segundo o natural, mas segundo a sua lembrança, sem se preocupar necessariamente dos detalhes ou segundo um modelo iconográfico que seguiam mais ou menos fielmente" (REDDÉ, 1986: 12); e "os textos oferecem-nos por vezes listas de nomes de navios, mas em regra geral, não são senão simples listas sem a menor descrição. Os monumentos, por outro lado, mostram-nos navios mas sem que possamos saber, salvo a excepção do mosaico de Altiburos, de que navios se trata. E mais, cada vez que nos encontramos em presença de uma representação figurada, e sobretudo para os mosaicos, estamos no direito de nos colocarmos duas questões: o documento é original ou não é senão uma cópia de um documento anterior ?; o documento é uma representação fiel da realidade? À primeira destas questões pensamos que no conjunto pode responderse pela afirmativa, mas para a segunda, tudo depende da arte e da ciência do autor do monumento" (RougÉ, 1966: 73). Sobre a mesma questão, embora referente a aspectos de pormenor, merece referir-se também o apontamento de B. Rosen (1986).

Continuando a interrogação sobre o valor intrínseco e extrínseco da representação iconográfica da barca de Sta. Vitória, não poderia agora deixar de ser referido - em reforço das opiniões contraditórias que tem envolvido a sua interpretação (e que Mercedes Torres Carro não refere no seu trabalho) - o facto de alguns autores considerarem que a barca tem a proa virada para o lado direito, ao invés do que considera aquela A. e Luís Chaves. Cabe, nesta ordem de ideias, a afir- 
mação de Lucien Basch (1975: 238), feita a propósito da representação da posição dos remadores nos navios antigos, que é uma questão muito controversa em iconografia e arqueologia navais, de que "Quanto ao autor do mosaico de Ameixial (no Museu de Belém, Portugal), da época romana, a sua obra é de uma qualidade tão medíocre que não se pode decidir se ele errou ou teve razão em representar os seus remadores voltados para a frente" $i^{2}$ ). Assinale-se assim que este A. considera a proa do lado direito.

Mas a questão da posição/orientação da embarcação traduzida na caracterização da extremidade tida como proa por aquela A. - não só quanto ao ponto de vista da sua orientação (esquerda/direita) - mas também quanto ao ângulo de observação (perfil/perspectiva) não se encontra esgotada. Com efeito, desta extremidade, resta ainda explorar uma outra perspectiva, que se prende com questões de forma e estrutura, numa óptica diferente das de Lucien Basch e Mercedes Torres Carro que, embora de modo diverso, interpretam ambos a forma das duas extremidades da embarcação como sendo arredondadas, no prolongamento da quilha.

Ora, curiosamente, foi o próprio autor da descoberta do mosaico, Luís Chaves, que enunciou desde o início uma outra interpretação, ao referir que "tf proa tinha esporões para aproar o navio inimigo; este navio denuncia o pormenor na protuberância angular da vante da quilha" (: 54, nota 2). Esta interpretação implica portanto que a extremidade da esquerda seja a proa e que esta se encontre rigorosamente de perfil (tornando-se necessário no entanto admitir uma considerável margem de liberdade iconográfica, dado que a representação, assim interpretada, tem de ser considerada muito tosca e distorcida, assaz diferente dos modelos iconográficos correntes para a época e para este pormenor típico, o que não pode ser explicado aqui por qualquer constrangimento do campo iconográfico). Nesta óptica de Luís Chaves seria pois uma embarcação de proa côncava, formal e estruturalmente diferente da pressuposta por Mercedes Torres Carro.

Neste ponto, torna-se oportuno situar, em linhas gerais, a questão dos barcos da época romana com estes dois tipos de proa, tomando

(2) Partilha a mesma opinião (expressa em carta pessoal) sobre a posição da barca de Sta. Vitória o autor a quem L. B. responde com o artigo supracitado, e a quem agradeço estas informações: TiLley, A. F. - Rowing in the ancient Mediterranean: a new aspect. "The Mariner's Mirror", 59.1: 96-99, 1973.

Conimbriga, 32-33 (1993-1994), 247-261 
como ponto de partida o estudo de Paul-Marie Duval (1949) sobre o mosaico de Altiburos: "Recordemos a importância da sua descoberta. Ele fornecia-nos vinte cinco tipos de embarcações diferentes, de dimensões permitindo largamente o estudo (0m70 a lmlO), e das quais vinte e duas levavam nomes, que, na verdade, eram na maioria já conhecidos pelos textos: nomes genéricos de navios romanos que dadas as características do mosaico permitiam situar o uso na segunda metade do II século do Império; navios de alto mar, barcos de pesca e embarcações fluviais, como o anunciam sobre três lados conservados do mosaico as representações de um deus-rio, do litoral onde se encontram pescadores, e de Oceano. Mas as formas eram quase todas desconhecidas, se bem que elas viessem alinhar-se em duas grandes categorias tradicionais: os navios "redondos", que aqui chamaremos simétricos, de duas extremidades igualmente arredondadas e levantadas; os navios "longos ", ou melhor: assimétricos, em que uma única extremidade é arredondada e levantada, a outra sendo angulosa, senão mesmo ponteaguda na base” (: 121), “...assim, que o navio seja simétrico ou assimétrico, o seu lado arredondado é o trazeiro, e, no navio assimétrico, que não é de nenhum modo o apanágio da marinha de guerra, mas que se encontra apto a todas as funções, o lado anguloso é afrente: tal é a lição dos documentos e dos técnicos" (: 132).

Com efeito, a documentação iconográfica e a evidência arqueológica convergem na demonstração desta coexistência tipológica, merecendo salientar-se, quanto à primeira, a título de exemplo, as representações simultâneas, lado a lado, destes dois tipos de embarcações, em mosaicos da Praça das Corporações de Ostia e no arco do Mercado de Lepcis Magna; quanto à segunda, que resulta principalmente do desenvolvimento da arqueologia subaquática nas últimas décadas, no caso de navios de guerra, raros são os testemunhos conservados, devido à ausência das cargas que caracterizam as embarcações de comércio e que cobrem, protegendo, a maioria dos cascos de navios antigos afundados. Até há bem pouco tempo, o único caso conhecido de um casco de navio de guerra antigo era o de Marsala, na Sicília (Frost, 1976), típico de um navio "assimétrico", com a particularidade notável de ter conservado intacta a estrutura de implantação do esporão.

No que respeita a navios de comércio "simétricos" ( $\left.{ }^{3}\right)$, refiram-se,

(3) Permitimo-nos, com três exemplos, balizar esquematicamente um milénio e meio de história naval. De salientar que os dois últimos exemplos representam marcos 
entre numerosos exemplos, os de Kyrénia (KATZeV \& KATZeV, 1987), de Yassi Ada I (BASS \& DoORNINCK et al, 1972) e de Serce Liman (STEFFY, 1988). Finalmente, como navio de comércio "assimétrico" típico, refira-se o da Madrague de Giens (TCHERNIA \& POMEY \& HESNARD, 1978 e PoMeY, 1982), cujo perfil longitudinal (Fig. 4) apresenta urna espantosa analogia com a embarcação representada num mosaico das termas de Temetra (Fig. 5) - o que demonstra paradigmaticamente também o rigor possível do documento iconográfico: "Seja como for, as convergências parecem-nos suficientemente numerosas para se poder identificar o navio da Madrague de Giens com este grande veleiro do mosaico das termas de Temetra. O interesse desta comparação é duplo: no plano arqueológico, ela permite-nos conhecer com precisão o tipo do navio da Madrague de Giens, e no plano iconográfico ela mostra que estamos em presença, com este mosaico, de uma representação fiel e não fantasista de um tipo de navio bem reaF (POMEY: 150).

Quanto à nave de Sta. Vitória, se tivermos simultaneamente em atenção a "imperícia" e a "mediocridade" (referidas respectivamente por Mercedes Torres Carro e por Lucien Basch) patentes na sua representação (de que as discrepâncias e incongruências já referidas são expressão), assim como as condicionantes próprias da representação iconográfica igualmente evocadas (ao que se deve adicionar sempre um factor de subjectividade interpretativa), encontramo-nos finalmente perante três hipóteses, todas elas parcialmente insatisfatórias: A de poder representar, ou pretender representar, a) - uma embarcação "simétrica", de proa para a esquerda; b) - idem, de proa para a direita; c) - uma embarcação "assimétrica" (de proa para a esquerda).

Torna-se portanto imperativo desenvolver e completar a pesquisa deste tema noutra direcção, dado que, do estrito ponto de vista da representação iconográfica, as possibilidades de análise parecem esgotadas. Será então ao nível da análise comparativa que terá de prosseguir a investigação.

decisivos para o conhecimento da evolução do navio antigo do ponto de vista da arquitectura naval, representando dois momentos bem caracterizados da transição da construção antiga, de tradição "casco primeiro", para a tradição moderna, de tipo "esqueleto primeiro”. Ver em RIETH (1984), que refere a bibliografia anterior sobre este assunto. 
Com efeito, são bem conhecidas as afinidades do mosaico de Sta. Vitória com os do Norte de África e em particular com os de Cherchel, Thaenae, Utica e Thugga (PoInssot: 223; AlARCÃo, 1974: 192; ToRRES CARRO: 93 e 102).

Saliente-se que, apesar de ser muito marcada a analogia da cena de Ulisses e as Sereias do mosaico de Sta. Vitória, especialmente com as dos mosaicos de Thaenae e de Thugga (Fig. 2), as embarcações representadas nestas cenas são manifestamente diferentes daquela (embora no de Thaenae não se possa determinar a forma da proa). Ora, se estas cenas deixam transparecer uma inspiração comum, tanto em termos gerais de composição como nos pormenores, seria natural que, no caso das embarcações representadas, tivesse sido igualmente seguido um modelo comum. Com efeito, o barco de Ulisses é de forma "assimétrica" em três dos quatro mosaicos norte-africanos acima referidos; portanto, deste simples ponto de vista, o mais natural seria que o de Sta. Vitória também o fosse. Tanto mais que são bem conhecidas as modalidades em que se processavam a execução e a divulgação dos padrões decorativos deste característico tipo de revestimento do mundo romano.

Referindo-se a este aspecto, Katherine Dunbabin (1978) observa que "o artifice teve certamente de seguir alguma espécie de cartão ou padrão pelo menos para as suas cenas mais complicadas; mas, como já foi referido, torna-se claro, dada a ocorrência de idênticos motivos em sítios bastante afastados (tal como em trabalhos noutros ramos), que eles eram frequentemente baseados num repertório distribuido pelo mundo romano, e não em esquemas desenhados de novo, por cada artista." (: 29); no entanto, refere que "isto pode significar ou contacto directo, ou o uso de modelos similares; os mosaicistas espanhóis poderiam ter experimentado independentemente e atingido resultados similares. Mas a coincidencia de paralelos sugere contactos mais estreitos; e como comparativamente há poucos destes mosaicos em Espanha, e nenhum sinal de um desenvolvimento local coerente, é óbvio que eles ilustram uma imitação consciente do estilo africano" (: 220). Saliente-se, no entanto, que no entender desta A. não se trata de uma imitação no sentido literal, "..mas antes um intercâmbio geral de ideias, e provavelmente muitas vezes de trabalhadores...” (: 22). Evidência aliás de que entre o Norte de África e a Lusitânia ocidental se reflecte uma intensidade de “...relações culturais e económicas que o estudo das cerâmicas, dos vidros e até da arquitectura demonstram” (ALARCÃo, ibidem). 
No entanto, no caso do mosaico de Sta. Vitória não nos encontramos simplesmente perante temas decorativos de inspiração norte-africana. Os seus medalhões ou painéis decorativos não foram executados no local, apenas terão sido aí montados (DUNBABIN: 29), tendo sido juntos e completados com tessellae feitas do típico calcário branco da região $\left(^{4}\right)$. Trata-se então de painéis do tipo emblema, certamente do género pseudo-emblemata, importados de algures, de um atelier de uma região que não é possível ainda identificar - restandomos apenas a presunção de uma origem norte-africana.

Finalmente, para o equacionamento completo deste problema, não é irrelevante realçar a situação geográfica de Sta. Vitória. E não só por razões de "interioridade" - embora, no caso concreto de uma embarcação, fosse mais lógico em áreas costeiras ou portuárias, mais apropriadas à presença de embarcações de maior porte e dignidade, poder beber-se a fonte de inspiração e manter aproximada a relação entre o cartão (ou medalhão) e a realidade - preocupação óbvia de qualquer artista de primeira categoria. Aliás, quando Claude Poinssot observa que "a degradação maior ou menor de um motivo, relativamente a um cartão original, não é um elemento de datação muito sólido, sobretudo quando se trata de obras provindas de sítios muito afastados geograficamente uns dos outros" (: 223), vem num certo sentido corroborar justamente aquela ideia.

Mas temos de considerar a situação geográfica por outra razão: porque para entender o significado de um mosaico, particularmente quando se trata de um exemplar com esta carga simbólica, não é irrelevante a consideração do seu "meio ambiente". Como refere Katherine Dunbabin "é de notar que não encontramos em Africa o mesmo uso do mosaico para todos os géneros de finalidades didácticas como se encontra nos mosaicos a preto-e-branco de Ostia, que funcionam como emblemas de loja (logotipos, diríamos - N.A.), publicidade de negócios, (...), e uma variedade de outras funções. Com os mosaicos africanos, quase sem excepção, a decoração permanece a finalidade primária" (: 25). E é esta, sem sombra de dúvida, a justificação funcional do mosaico de Sta. Vitória.

$\left(^{4}\right) \quad$ Agradeço esta informação a Carlos Beloto, técnico especialista de conservação e restauro do Museu Monográfico de Conimbriga, que tem vindo a efectuar um trabalho de fundo nos mosaicos de todo o País, e em particular nos do Museu Nacional de Arqueologia, como o de Sta. Vitória. 
Assim, do mesmo modo que nas representações dos barcos em Ostia e de Oceano em Altiburos ou em Faro (5), se exprimem significados apotropaicos, propiciatorios e religiosos, nas de um Oceano ou de uma barca de Ulisses do mosaico do balneário da villa lusitano-romana de Santa Vitória do Ameixial exprime-se fundamentalmente uma função decorativa. Daí que, num certo sentido, se possa encontrar desvanecida, do ponto de vista iconográfico, a dignidade épico-simbólica da nave de Ulisses. A este proposito, Mercedes Torres Carro observa justamente que ${ }^{44}$ na realidade, a presença deste tipo de embarcação na cena da Odisseia não é corrente. Normalmente nas representações mitológicas preferem-se uns modelos estabelecidos de barcos que costumam ser mais luxuosos e correspondem melhor à importância da cena representada. Neste caso o modelo que se nos oferece parece tirado mais da realidade e assemelha-se mais a uma barcaça de pescador que a um navio próprio para transportar Ulisses nas suas aventuras" (: 96).

Pelas razões expostas e pelos dados actualmente disponíveis, poder-se-iam portanto apontar, como conclusões, que a representação da cena de "Ulisses e as Sereias" do balneário de Santa Vitoria do Ameixial parece inspirar-se num modelo-padrão ou arquétipo comum aos mosaicos norte-africanos com tal cena, entre os quais o de Thugga. Daí que se possa reconheçer, embora muito distorcido, o traço de um vago perfil assimétrico. No entanto, a representação da embarcação do mosaico de Sta. Vitória só muito longinquamente tem a ver com o "arquétipo" dos modelos congéneres norte-africanos, sendo praticamente impossível distinguir o componente real do imaginário em que se baseou o artista na sua execução.

Esta representação parece traduzir, mais do que a ${ }^{44}$ imperícia" ou ${ }^{44}$ mediocridade" do artífice ou do artista, uma anárquica mas autêntica colagem de elementos, no sentido técnico-artístico do termo, como se

$\left(^{5}\right) \quad$ "Este destino público do edificio explica sem dúvida a escolha dos que o encomendaram, quer dizer, a versão mais "geográfica" do tema. Oceano, pai de todas as águas que faz nascer os Ventos, cujo sopro favorece a navegação, o comércio. Cosmologia e geografia humana inspiram este mosaico (*) e não a mitologia ou a cenografia. Não temos também aqui uma cabeça simplesmente decorativa, como a máscara de Oceano pode tornar-se em contextos menos marcados. ” (LANCHA: 119-120);

(*): “Como no mosaico do catálogo de Altiburos.." . N.A.: diz Dunbabin (: 153): "Nestes pavimentos (de Altiburos) não pode haver dúvida que a máscara é a de um deus, e não é olhada simplesmente como um motivo decorativo". 
os traços do modelo-padrão se tivessem desvanecido perante uma improvisação provinciana de estilo marcadamente naife possivelmente inspirada em formas tiradas de modelos de barcos de tradição fluvial de presumível interioridade. Nesta perspectiva tudo concorre para admitir que, sobre o modelo-padrão, foi executada a representação de uma embarcação de inspiração real, em posição inversa (com a proa para a direita), com a vista de popa a "ajeitar-se" tanto quanto possível, ao vago traço da concavidade própria de uma proa de navio assimétrico. Daí que o artista tenha optado (desajeitadamente, diga-se mais uma vez), por uma típica vista a $3 / 4$ de popa a bombordo, em que uma parte simétrica, de estibordo, fica à vista (desenhando uma curva que vagamente se entendeu poder corresponder à da proa terminando em esporão, do arquétipo).

Assim sendo, parece doravante insensato continuar a procurar na nave de Ulisses do mosaico de Sta. Vitória do Ameixial aquilo que provavelmente ela não é, nunca foi, nem será: um "barco".

Como refere S. C. Humphreys no final do seu artigo (: 79, nota 9), "devíamo-nos sempre lembrar, ao interpretar a evidência iconográfica, a observação de Matisse a uma visitante que estava criticando um dos seus nus, por falta de realismo: 'Minha senhora, parece-me que está cometendo um erro. O que está a ver não é uma mulher, é um quadro,".

\section{BIBLIOGRAFIA}

AlarCão, J. de - Portugal Romano. Lisboa, 1974.

Barata, J. da G. P. - Estudos dos navios do políptico de Santa Auta. Centro de Estudos de Arte e Museologia. Lisboa, 1972.

Basch, L. - De la survivance de traditions navales phéniciennes dans la Mediterranée de nos jours ou des rêves à la réalité. "The Mariner's Mirror", 61.3: 229-253. 1975 .

Bass, G. F. \& VAn Doonninck Jr., F. H. et al. - $Y$ as si Ada I. A seventh century Byzantine shipwreck. The Nautical Archaeology Séries, 1. Texas A\&M University Press, College Station. Texas, 1972.

Casson, L. - Ships and seamanship in the ancient world. Princeton, 1971.

Chaves, L. - Estudos lusitano-romanos. A villa de Santa Vidria do Ameixial (Concelho de Estremoz). Escavações em 1915-1916. "O Arqueólogo Português", 30: 1487. Lisboa, 1938 (1956).

Dunbabin, K. M. D. - The Mosaics of Roman North Africa. Oxford, 1978.

Duval, P.- M. - La forme des navires romains d'après la mosaïque d'Althiburus. "Mélanges de l'Ecole Française de Rome et d'Athènes", 61: 119-149. 1949. 
Frost, H. - Lilybaeum. "Notizie Degli Scavi di Antichità". Sup. Voi. 30 (1976). Academia Nazionale dei Lincei. Roma, 1981.

Humphreys, S.C. - Artists' mistakes. "International Journal of Nautical Archaeology", 7.1: 78-79. 1978.

Katzev, M. L., Katzev, S. W. - Kyrénia II. Research on an ancient shipwreck comes full circle in a full-scale replication. An ancient ship sails again. Hellenic Institute for the Preservation of Nautical Heritage (: 4-9). Piraeus, 1987.

Lancha, J. - O mosaico "Oceano" descoberto em Faro (Algarve). "Anais do Município de Faro", 15: 111-124. Faro, 1985.

Poinssot, C. - Quelques remarques sur les mosaïques de la maison de Dionysos et d'Ulysse à Thugga (Tunisie). In "La Mosaïque Greco-romaine", I. Paris, 1965.

Pomey, P. - Le navire romain de la Madrague de Giens. Comptes-rendus de l'Academie des Inscriptions et Belles-Lettres (: 133-150). Paris, 1982 (jan.- mar.).

REDDÉ, M. - MARE NOSTRUM. Les infrastructures, le dispositif et l'histoire de la marine militaire sous l'empire romain. Bibliothèque des Ecoles Françaises d'Athènes et de Rome, 260. 1986.

RiteH E. - Principe de construction "charpente première" et procédé de construction "bordépremier au XVIIe siècle. "Neptunia”, 153: 21-31. Paris, 1984.

Rosen, B. - An Incorrect Representation of a Sailing Boat in the Madaba Mosaic. "Israel Exploration Journal", 36: 97-98. Jerusalem, 1986.

Rougé, J. - Recherches sur l'organisation du commerce maritime en Mediterranée sous l'empire romain. Paris, 1966.

STEFFY, J. R. - Reconstruction the hull. "The glass wreck: an 11th century merchantman", INA Newsletter, voi. 15, n. ${ }^{\circ}$ 3, September 1988.

Tchernia, A., Pomey. P., Hesnard A. - L'épave romaine de la Madrague de Giens (Var). XXXIV Supplément à Gallia. Paris, 1978.

Torres Carro, M. - La escena de Ulises y las sirenas del mosaico de Santa Vitoria (Portugalf "Boletín del Seminario de Estudios de Arte y Arqueologia", 44: 89-102. Valladolid, 1978. 


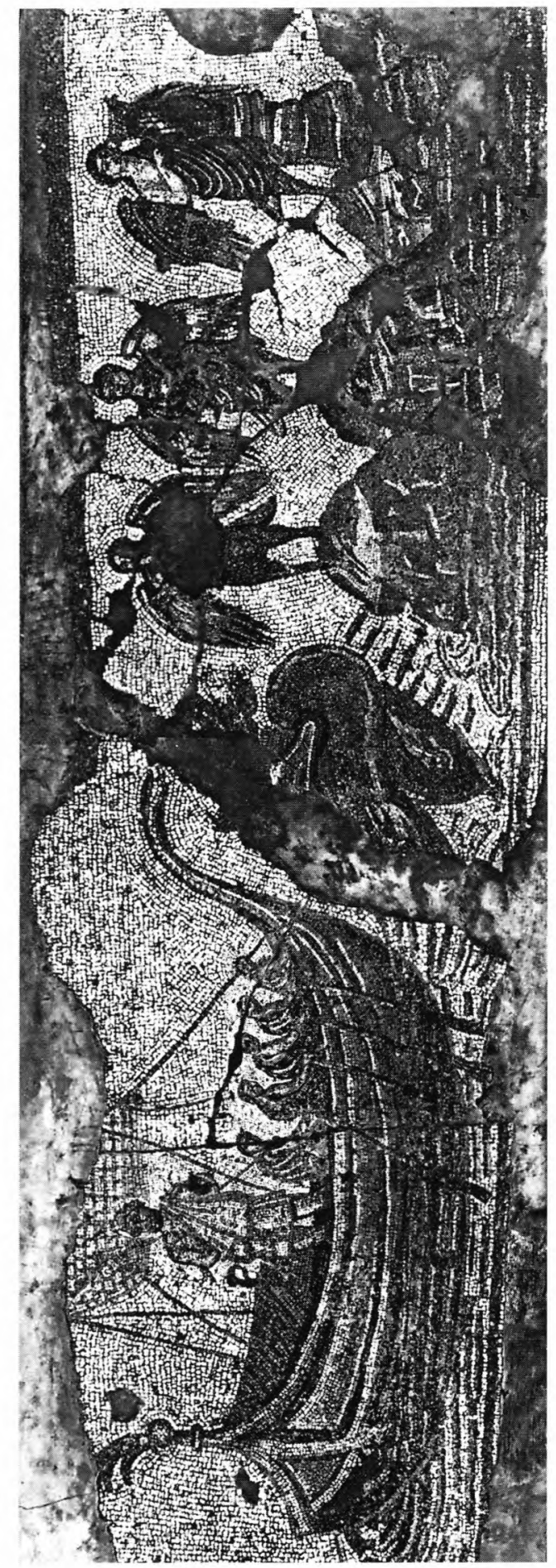

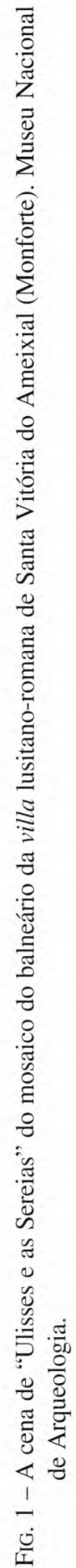




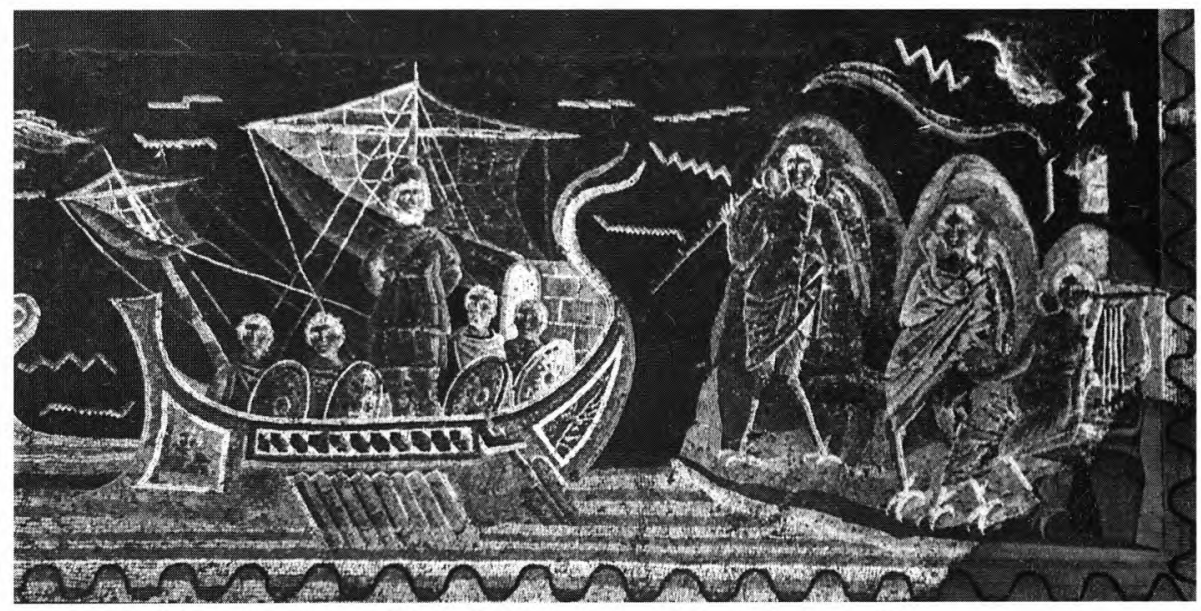

FIG. 2 - Representação da cena de "Ulisses e as Sereias" no mosaico de Thugga. Seg. Dunbabin

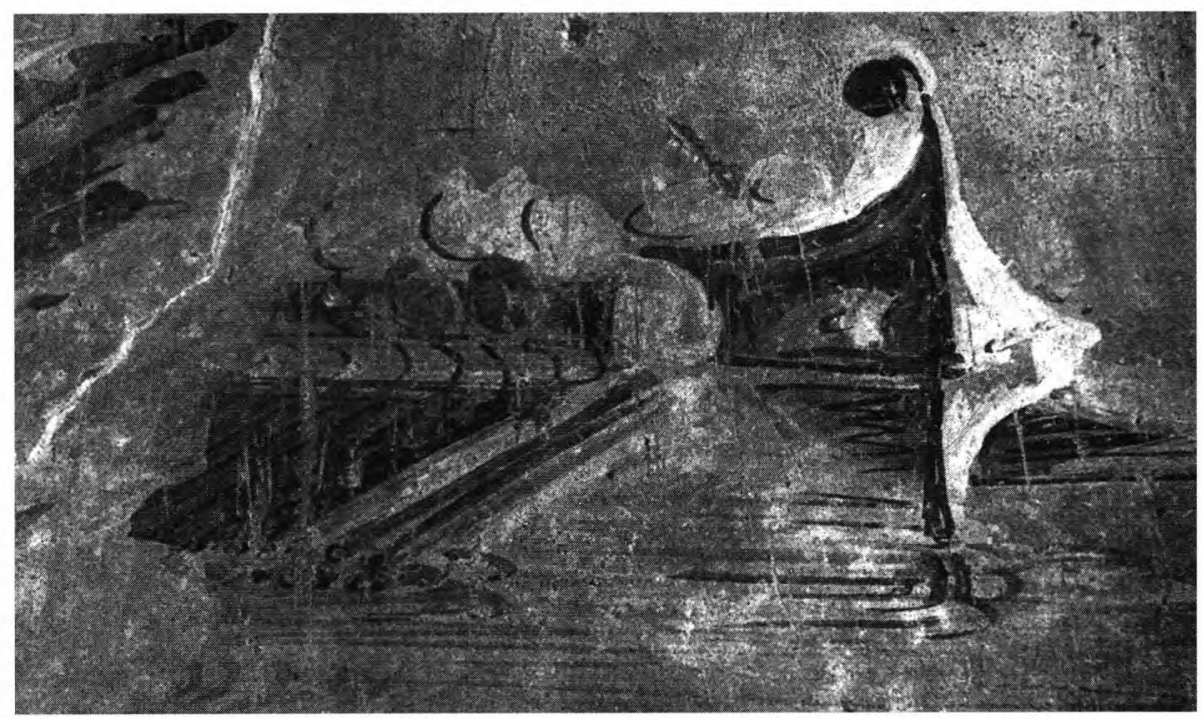

FIG. 3 - Pintura mural de Pompeia (Casa do Sacerdote Amandus). Seg. Reddé 


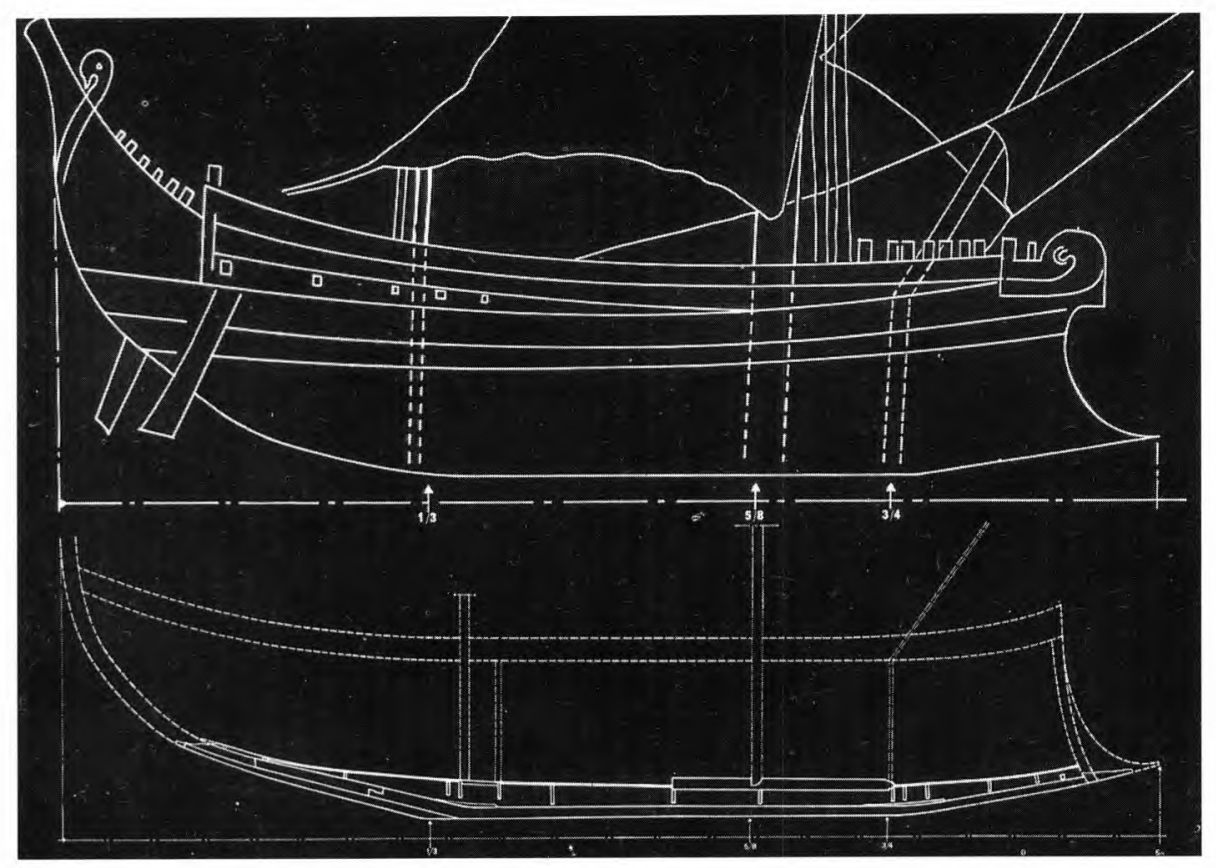

FIG. 4 - Reconstituição das linhas do navio da Madrague de Giens. Seg. F. Pomey

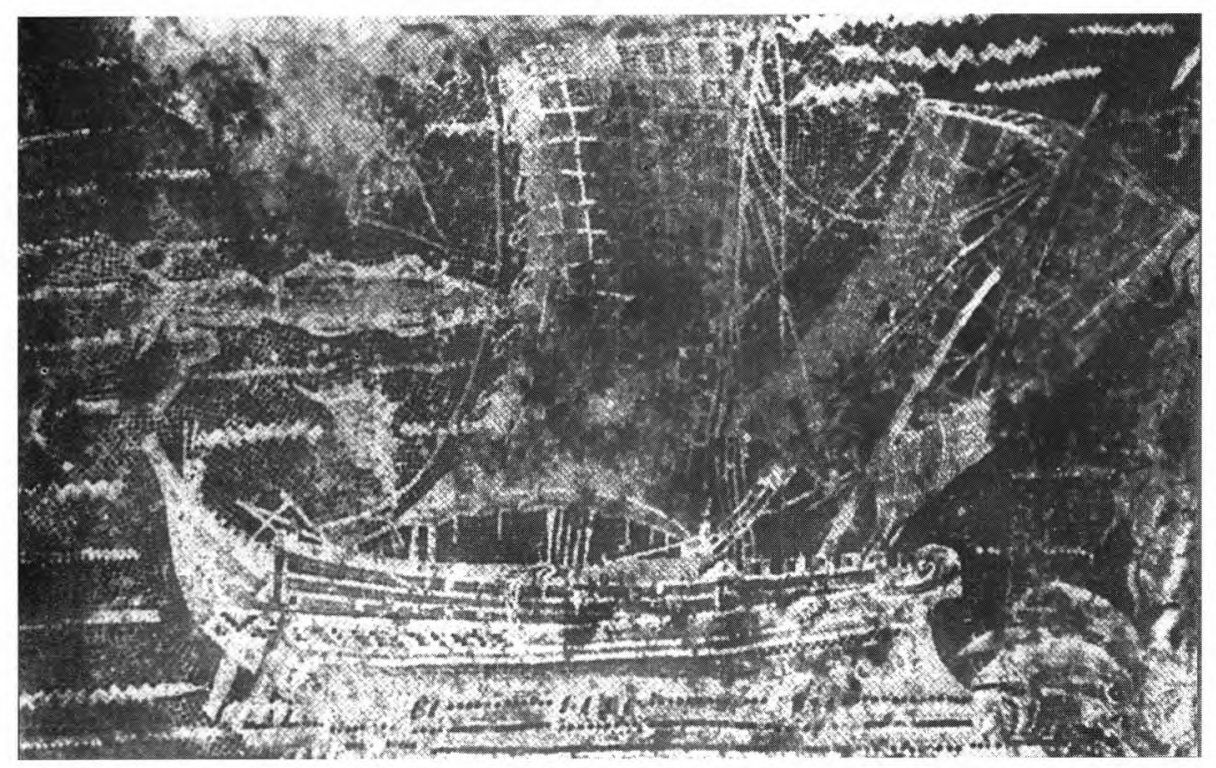

FIG. 5 - O navio representado no mosaico das termas de Temetra 